\title{
Open Medial Hoffa Fracture with Ipsilateral Femoral Shaft Fracture: Case Report
}

\author{
Abdullah Saad A Abdullah*, Nedal Alkhatib, Syed Imran Ghouri and Mohammed Mubarak Alkha- \\ yarin \\ Orthopedic Department, Hamad Medical Corporation, Qatar \\ *Corresponding author: Abdullah Saad A Abdullah, M.B.Ch.B, MRCS, Orthopedic Department, Hamad \\ Medical Corporation, Doha, Qatar, E-mail: abdullahsaad21@gmail.com
}

\begin{abstract}
Hoffa fracture is coronal plane fracture of the femoral condyle that affects the lateral femoral condyle much more than the medial. The combination of medial femoral condyle Hoffa fracture with ipsilateral femoral shaft fracture is very rare combination with only 3 cases were reported previously. This fracture type usually requires high energy trauma and it was reported following a motor injury. We reported a 53-year-old male, who was riding a motor cycle when he was hit by car and presented to the emergency trauma care as a polytrauma patient with open medial Hoffa fracture, ipsilateral femoral shaft fracture and knee ligamentous injury in addition to other injuries in his wrist, ankle and spine. The patient was treated for his fractures and ligamentous injuries followed by early mobilization.
\end{abstract}

\section{Keywords}

Hoffa fracture, Femoral condyle fracture, Intra-articular knee fracture, Femoral shaft fracture, Trauma, Knee injury

\section{Introduction}

Hoffa fracture was first described by Albert Hoffa in 1904 as a coronal shear fracture affecting the distal femoral condyle, more likely to be unicondylar type than bicondylar, also three times more likely to affect the lateral condyle rather than the medial condyle [1,2]. Hoffa fracture is considered as type 33-B3 according to AO/OTA fracture classification. The reported mechanism for medial Hoffa fracture is due to direct impact on the medial femoral condyle while the knee is in flexed position. Stable internal fixation is prerequisite to start early range of motion of the injured knee otherwise there is high chance of non-union, joint stiffness, instability and deformity with non-operative management $[3,4]$. In this case report we describe unique case of open medial Hoffa fracture with associated injuries.

\section{Case Report}

Our patient is 53-year-old male, previously healthy, was brought to trauma room in the emergency department of Hamad General Hospital, as a case of motor cyclist who was hit by a car from the left side. The patient was complaining of left body side pain including thigh, knee, leg, ankle and wrist pain. He was also complaining of upper lumbar back pain. No past medical or surgical history. He was conscious, oriented. His left wrist was swollen, tender with friction burn on the anteromedial aspect. Left thigh showed moderate swelling and tenderness, Left knee open lacerated wound $10 \mathrm{~cm}$ Gustillo type III a on the medial side, tenderness, unstable knee on gentile valgus stress with bloody oozing from the wound, Left ankle abrasions and tenderness over the medial malleolus, log-rolling was done to examine his back and revealed tenderness over the upper lumbar spine. Radiological investigations showed: Simple oblique left femur shaft fracture type $A O 32-A 2$, left medial Hoffa fracture type AO 33-B3 as shown in Figure 1, left distal radius styloid fracture AO 23-B1, left ankle fracture and L1 mild compression spine fracture. In the emergency department, the patient was managed by washing of the wound, antibiotic, analgesia, intravenous fluids and intramuscular tetanus toxoid. Close reduction and backslab plasters were applied for his left wrist and left ankle fractures. In addition skin traction applied for the left femur shaft

Citation: Abdullah ASA, Alkhatib N, Ghouri SI, Alkhayarin MM (2018) Open Medial Hoffa Fracture with Ipsilateral Femoral Shaft Fracture: Case Report. Trauma Cases Rev 4:059. doi.org/10.23937/2469$5777 / 1510059$

Received: February 22, 2018; Accepted: April 14, 2018: Published: April 16, 2018

Copyright: (C) 2018 Abdullah ASA, et al. This is an open-access article distributed under the terms of the Creative Commons Attribution License, which permits unrestricted use, distribution, and reproduction in any medium, provided the original author and source are credited. 


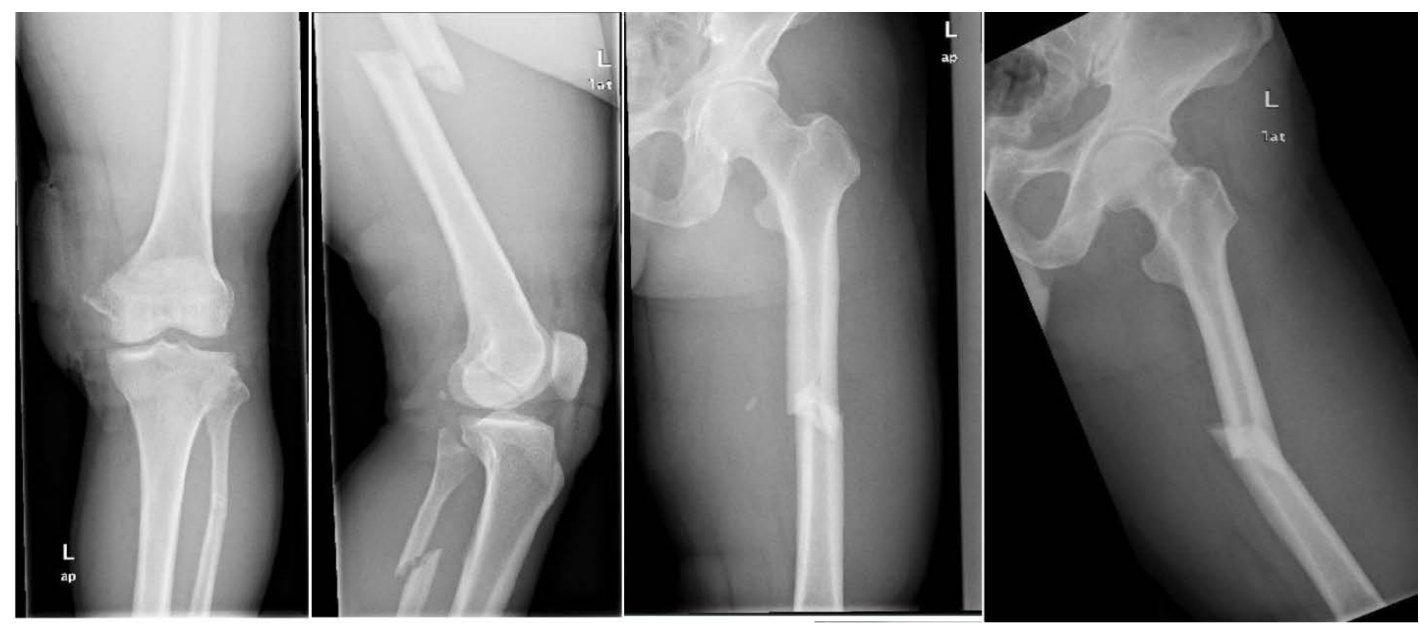

Figure 1: Left knee and femur X-rays at presentation.
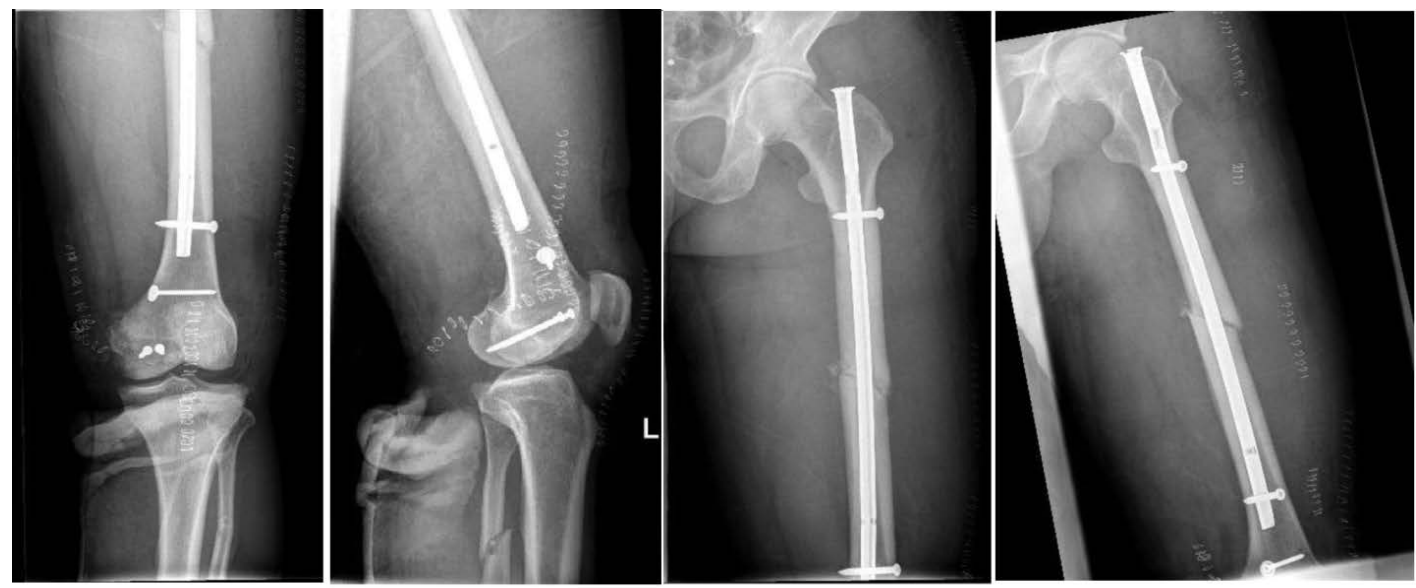

Figure 2: Left Knee and femur X-Rays postoperatively.

fracture. The patient was then transferred to the operating room where he underwent proper debridement of his left medial wound, exploration was done and wound extended using medial para-patellar approach for the medial femoral condyle, it was found that the patient had sustained medial collateral ligament (MCL) tear and tear for the anteromedial bundle of the anterior cruciate ligament $(\mathrm{ACL})$. Open Reduction and Internal Fixation (ORIF) for the medial Hoffa fracture was done using two cortical screws $3.5 \mathrm{~mm}$ diameter in antero-posterior direction through non-articulating part of the condyle which was stable when tested after fixation. The avulsion of the femoral attachment of the anteromedial bundle of the ACL was repair and it attachment was reconstructed by passing the sutures through the lateral femoral condyle, tightened and secured on a plastic button over the lateral surface of the left distal femur. The lacerated $\mathrm{MCL}$ was repaired and its femoral attachment was reconstructed and tightened over a screw. This was followed by antegrade nailing for the left femoral shaft fracture in the same session as shown in Figure 2. The patient was taken the later on another day to fix his left wrist and ankle. Postoperatively his recovery was smooth and his wounds healed without complications. He was started on left touch weight bearing ambulation using Canadian frame while he was in the hospital. The patient was followed up in the clinic and his fractures are healed and the patient is ambulating unaided however his knee ROM is 8-123 on the left side compared to $0-132$ on the right side.

\section{Discussion}

Hoffa Fracture is coronal plane fracture of the femoral condyle [1]. This fracture configuration is more commonly affecting the lateral femoral condyle due mechanical configuration and the normal valgus knee alignment following a high energy trauma like road traffic accident or fall $[5,6]$. This case is very rare and after reviewing the English literature we found three patients who sustained medial Hoffa fracture with ipsilateral femoral shaft fracture in two similar reports, and by now, this is the fourth patient. The previously reported 3 cases were closed fractures but this patient had an open injury, also none of them have reported similar associated ligament injuries [7,8].

Medial Hoffa fracture with ipsilateral femoral shaft fracture is very easily missed on initial presentation and might be discovered after application of skeletal traction or after femoral shaft fixation as reported in other cases. CT scan might be needed if there is any suspi- 
cion of knee injury that is not clear on plain radiograph. Anteroposterior and lateral radiograph of the knee is diagnostic in about $70 \%$ of the cases only [7-9]. It was advised that Hoffa fracture is to be treated operatively even if they are not displaced as they are liable for displacement $[5,10]$. Sometimes the typical anterior-posterior screws fixation alone for the Hoffa fracture is not sufficient when the fracture has metaphyseal extension which might need an additional buttress plate fixation but in our case it was not required as the fracture did not have a metaphyseal extension [5,10-12]. In this patient antero-posterior screws was used for ease of access due to the patient other injuries rather than the biomechanically stronger postero-anterior screws [13].

The Case report was approved by Medical Research Center, MRC-04-17-194.

\section{Consent}

The patient gave his consent to the publication of this case.

\section{Funding}

No Source of Funding.

\section{Conflict of Interest}

No conflict of Interest.

\section{References}

1. Hoffa A (1904) Textbook of fractures and dislocations. Publisher of Ferdinand Enke, Stuttgart, 451.

2. Holmes SM, Bomback D, Baumgaertner MR (2004) Coronal fractures of the femoral condyle: A brief report of five cases. J Orthop Trauma 18: 316-319.
3. Ostermann PA, Neumann K, Ekkernkamp A, Muhr G (1994) Long-term results of unicondylar fractures of the femur. $J$ Orthop Trauma 8: 142-146.

4. Maruthi CV, Nikhil Gupta, Venugopal N, Nanjundappa HC, Siddalingaswamy MK (2013) Medial condylar hoffa fracture in left knee joint: Case report. Sch J App Med Sci 1: 10751077.

5. Lewis SL, Pozo JL, Muirhead-Allwood WF (1989) Coronal fractures of the lateral femoral condyle. J Bone Joint Surg $\mathrm{Br}$ 71: 118-120.

6. Flanagin BA, Cruz Al, Medvecky MJ (2011) Hoffa fracture in a 14-year-old. Orthopedics 34: 138.

7. Miyamoto R, Fornari E, Tejwani NC (2006) Hoffa fragment associated with a femoral shaft fracture. A case report. J Bone Joint Surg Am 88: 2270-2274.

8. Gong YB, Li QS, Yang C, Li SQ, Liu JG, et al. (2011) Hoffa fracture associated with ipsilateral femoral shaft fracture: Clinical feature and treatment. Chin J Traumatol 14: 376-378.

9. Nork SE, Segina DN, Aflatoon K, Barei DP, Henley MB, et al. (2005) The association between supracondylar-intercondylar distal femoral fractures and coronal plane fractures. J Bone Joint Surg Am 87: 564-569.

10. Holmes SM, Bomback D, Baumgaertner MR (2004) Coronal fractures of the femoral condyle. J Orthop Trauma 18: 316-319.

11. Dhillon MS, Mootha AK, Bali K, Prabhakar S, Dhatt SS, et al. (2012) Coronal fractures of the medial femoral condyle: A series of 6 cases and review of literature. Musculoskelet Surg 96: 49-54.

12. Agarwal S, Giannoudis PV, Smith RM (2004) Cruciate fracture of the distal femur: The double Ho a fracture. Injury 35 : 828-830.

13. Jarit GJ, Kummer FJ, Gibber MJ, Egol KA (2006) A mechanical evaluation of two fixation methods using cancellous screws for coronal fractures of the lateral condyle of the distal femur (OTA type 33B). J Orthop Trauma 20: 273-276. 